\title{
Heat Transfer Enhancement in a Smart Phone
}

\author{
K. Abinav ${ }^{\# 1}$, P. Palani Rajeshwar ${ }^{* 2}$, Jerry S Punnoose ${ }^{\# 3}$, Joseph Daniel ${ }^{\# 4}$, \\ M. Sreekanth ${ }^{\# 5}$

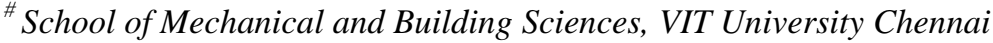 \\ Vandalur-Kelambakkam Road, Chennai \\ Iabinav.k2012@vit.ac.in \\ ${ }^{2}$ palanirajeshwar.p2012@vit.ac.in \\ 3 jerry.shaji2012@vit.ac.in \\ joseph.daniel@vit.ac.in \\ ${ }^{5}$ manavalla.sreekanth@vit.ac.in
}

\section{ABSTRACT}

Smart phones are posed with heat transfer problems due to the space and weight limitation and also due to ever increasing processer speed. In this work, heat transfer in a Xiaomi Mi4i smart phone model has been studied using CFD. Studies at various operating conditions like (i) Basic operation, (ii) Usage of all applications, and (iii) Usage of internet have been considered. Certain hot spots have been identified and solutions to reduce temperature have proposed. Also, a scaled up model of the smart phone has been set up to measure the temperature distribution. It has been found that using copper and aluminium heat spreaders with sufficiently sized and numbered heat taps contributes to reduction in temperatures and thereby would be useful in using the mobile phone with lesser discomfort and yield longer life for the electronic components.

Keyword: Smart Phone, Heat Transfer, Heat Spreaders, Heat Taps, Computational Fluid Dynamics

\section{INTRODUCTION}

Smart phones are a way of life these days. Cramming up the phone with several applications (Apps) demands an increase in processing speed. At the same time, the cut throat competition among manufacturers to sell more and make profits leads to reduction in cost, which has a direct influence on the materials used. Higher processing speed and larger storage capacities in the limited space offered by a smart phone (maximum of 5.5 inch display) puts huge pressure on the heat dissipation abilities of the phones. Heat dissipation is important from the electronics view point as the material characteristics tend to change at elevated temperatures and hence the performance deteriorates. Further, higher temperatures result in user discomfort and the associated health issues. These issues form the motivation for better thermal management in smart phones.

Thermal analysis for phones has been considered by previous researchers. Lee et al. [1] studied the impact of volume to size ratio on chip temperature rise for handheld devices. It is noted that surface temperature of the device (skin temperature) reduces with increase in size of the handheld system. Some case thermal enhancements were also considered. Luo et al. [2] performed measurements on an actual phone and developed a detailed numerical model as well as a resistance network model of the phone. Thermal enhancements through higher thermal conductivity materials are suggested but no results are presented. The detailed numerical model is conduction based and uses approximations for heat transfer coefficients on the phone's surface. Grimes et al. [3] investigated the integration of an active fan into a small phone. Up to $60 \%$ higher power dissipation was possible at a fixed surface temperature constraint using the fan with realistic flow blockages. Saroj et al.[4] concluded that for every $2^{\circ} \mathrm{C}$ temperature rise, the reliability of a silicon chip will be decreased by about $10 \%$. The major cause of an electronic chip failure is due to temperature rise $(55 \%)$ as against other factors which accounts $20 \%$ vibration, $19 \%$ humidity and $6 \%$ dust. So it's a great challenge for the packaging engineers to remove the heat from the electronics very efficiently. Victor Chiriac [5], et al of Qualcomm Technologies(2015) proposed a new dimensionless thermal spreading effectiveness metric for mobile devices, named CTS (Coefficient of Thermal Spreading). The CTS value quantifies the internal thermal spreading of mobile devices, and is a specific metric to improve the thermal design. Yusuke Tomizawa [6] et al of Beijing (2015), studied the application of PCM sheets in mobile phones. They concluded that due to higher thermal conductivity of PCM sheets than PE sheets, the rise in temperature for outer case was less thus causing less discomfort to the user. Haoshan Ge [7] and Jing Liu of Beijing (2013) observed that Gallium could not be used as a PCM for cases where ambient temperature is greater than $30^{\circ} \mathrm{C}$ as its melting point is $29.76^{\circ} \mathrm{C}$.Conventional $\mathrm{PCM}$ 
materials like paraffin, n-icosane ,sodium sulphate decahydrate also can't be use as a PCM because of a very low melting point. Liquid metal alloys with different melting could be used as an alternative. Siva P. Gurrum [8] et al of Texas instruments Dallas(2012),observed that metallic spreaders and gap filler pads can create thermal paths necessary for lower junction temperature. He concluded that significant temperature reductions are possible with higher thermal conductivity middle-plate and gap filler pads for the skin temperature. Maciej [9] of Poland (2011) concluded that electronics cooling with the incorporation of PCM (phase change material) was much better than PCM based heat sinks with simple PCM containers. All of this could be achieved with a small amount of PCM. Ronan Grimes, Ed Walsh[10] et al of Ireland (2009) observed that although the application of fan bought about a $75 \%$ increase in allowable heat dissipation but it resulted in $20 \%$ power consumption. This would lead to frequent charging of smart phone. Egan, Eric, Amon and Cristina. H[11]., (2000), in order to understand the thermal phenomena of embedded electronics design and to explore the thermal design space, analyzed the finite element numerical simulations, physical experimentation, and analytical models. The results show that the exposed surface area of the heat spreader and the conductivity of the substrate are the most important parameters affecting the thermal performance of the embedded electronic artifact.

Experiments too were conducted in a disassembled cell phones and physical models. Simionescu, F., Meir, A. J., and Harris, D. K. [12] of France (2006), studied a heat source (electronic chip) placed on the top surface of a flat thermal spreader which is cooled by convection on the opposite surface. They found an optimal convection heat transfer coefficient yielding maximal heat removal from the chip an optimal control technique. They control the solution of the heat equation with the convective boundary condition, taking the heat transfer coefficient as the control. They used a conjugate gradient method to solve the optimal control problem. The results show that the temperature distributions corresponding to the controlled solution are lower and display a flatter profile than those corresponding to the uncontrolled solution. T.T Lee [13] of Beijing (1998) observed that adding heat spreader in the cell phone reduced the component temperature. He also ignored the air circulation inside in the phone, but the use of heat spreaders would lead to increase in weight of smart phone. He validated his simulation results with an experimental setup where he created a cell phone mock up.

This work attempts to study the heat transfer in a Xiaomi Mi4i smart phone using CFD and experimental temperature measurement. Also, metal heat spreaders made of copper and aluminium have been tried to find out if there is an improvement in heat transfer or not. The spreaders have been modified by introducing heat taps to study the enhancement in heat transfer. Finally, a scaled up replica of the smart phone has been fabricated and the temperature has been measured using a thermal imaging camera. Studies were carried out at various operating conditions of the smart phone viz. (i) Basic Operation with least power consumption, (ii) Situation when all the Apps are running and (iii) During interned access.

\section{METHODOLOGY}

The phone was dismantled at a service centre to model chipset components. The smart phone was modelled in Solidworks 14. The following components were modelled as per dimensions: (i) Chipset, (ii) Battery, (iii) Display and (iv) Cover.

Mathematical Formulation:

Coefficient of thermal spreading (CTS )

$\mathrm{CTS}=\frac{T_{\text {avg }}-T_{\text {ambient }}}{T_{\max }-T_{\text {ambient }}}$

$\mathrm{T}_{\text {avg }}$-Average Temperature $(\mathrm{K})$

$\mathrm{T}_{\text {ambient }}$-Ambient Temperature $(\mathrm{K})$

$\mathrm{T}_{\max }$-Maximum Temperature $(\mathrm{K})$

Convection equation

$q=h A\left(T_{1}-T_{2}\right)$

h-heat transfer coefficient $\left(\mathrm{W} /\left(\mathrm{m}^{2} \mathrm{~K}\right)\right)$

q-heat transferred(W)

$\mathrm{T}_{1}$-Temperature of object $(\mathrm{K})$

$\mathrm{T}_{2}$-Temperature of fluid(K)

General heat equation

$\frac{\partial u}{\partial t}=\alpha\left(\frac{\partial^{2} u}{\partial x^{2}}+\frac{\partial^{2} u}{\partial y^{2}}+\frac{\partial^{2} u}{\partial z^{2}}\right)+\frac{q}{C_{p} \rho}$

$\mathrm{u}(\mathrm{x}, \mathrm{y}, \mathrm{z}, \mathrm{t})$-temperature function $(\mathrm{K})$

$\alpha$-thermal diffusivity $\left(\mathrm{m}^{2} / \mathrm{sec}\right)$

$\mathrm{C}_{\mathrm{p}}$-specific heat $(\mathrm{J} / \mathrm{kg} . \mathrm{K})$

$\rho$-density $\left(\mathrm{kg} / \mathrm{m}^{3}\right)$

q-heat energy $(\mathrm{J})$

Fourier law of conduction

$\vec{q}=-k \nabla T$

$\vec{q}$ - local heat flux density $\left(\mathrm{W} \cdot \mathrm{m}^{-2}\right)$

$k$ is the thermal conductivity $\left(\mathrm{W} \cdot \mathrm{m}^{-1} \cdot \mathrm{K}^{-1}\right)$

$\nabla T$ is the temperature gradient $\left(\mathrm{K} \cdot \mathrm{m}^{-1}\right.$.)
Materials used
1. Lithium-battery
2. Silicon- chips
3. Germanium- PCB
4. Thermoplastic polycarbonate- outer casing
5. Copper-heat spreader 


\section{CFD Simulation:}

Circuit was modelled in Solidworks14. Since our area of interest was the chipset and motherboard, the mesh was refined at these areas. This is done to reduce computation time in Ansys WORKBENCH. The simulation was done in transient thermal module of ANSYS 16. Heat flux was given to the chips on the motherboard. Convection boundary condition with appropriate film coefficient values was given to the chip, motherboard, heat spreader and the outer case. The simulation was simulated for a time of 60 seconds at a maximum step of 0.1 second. The temperature profile for the cell phone was obtained as a result. Figure 1 shows the meshed model on the front side of the chipset.

\section{PAGE STYLE}

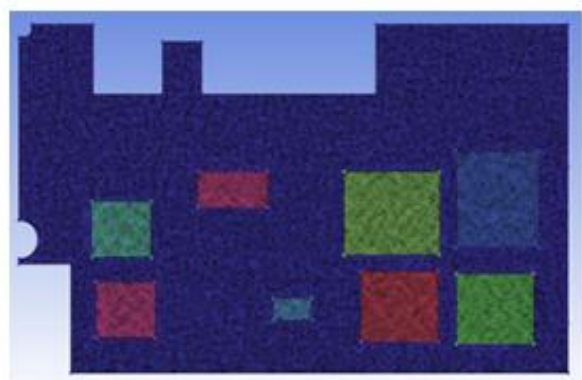

Fig. 1: Front View of the Chipset

\section{Experimental Set up:}

Previous studies have demonstrated that conduction is the most dominant mode of heat transfer in the phone case. Thermal management shall therefore focus on reducing conductive thermal resistance. Methods of system level thermal enhancement have been investigated; the addition of a high performance heat spreader to the case wall being one of them.

In this experiment, the main aim is to demonstrate the heat conduction phenomenon occurring inside the phone after metal heat spreaders are introduced. The materials used for this experiment are:

- Wooden board (20x15.5 inches)

- Mica heaters-4x(3x2 inches) and $4 \times(2 \times 2$ inches $)$

- Copper plates- $1 \mathrm{x}(9 \mathrm{x} 4$ inches $), 1 \mathrm{x}(9.1 \mathrm{x} 8.2$ inches $)$

- Aluminium plates-1x(10x9 inches),1(9.1 x8.2 inches)

- Bolts- 6 nos. of $6 \mathrm{~mm}$ diameter

Figure 2 below shows the schematic arrangement of the experimental setup. In the image, the wooden board represents the PCB, the mica heaters represent the processors and sub-processors on the back side of the chipset. The idea is that the peak temperatures attained by the main processors can be reduced by introduction of Copper and Aluminium plates of $5 \mathrm{~mm}$ thickness onto them.

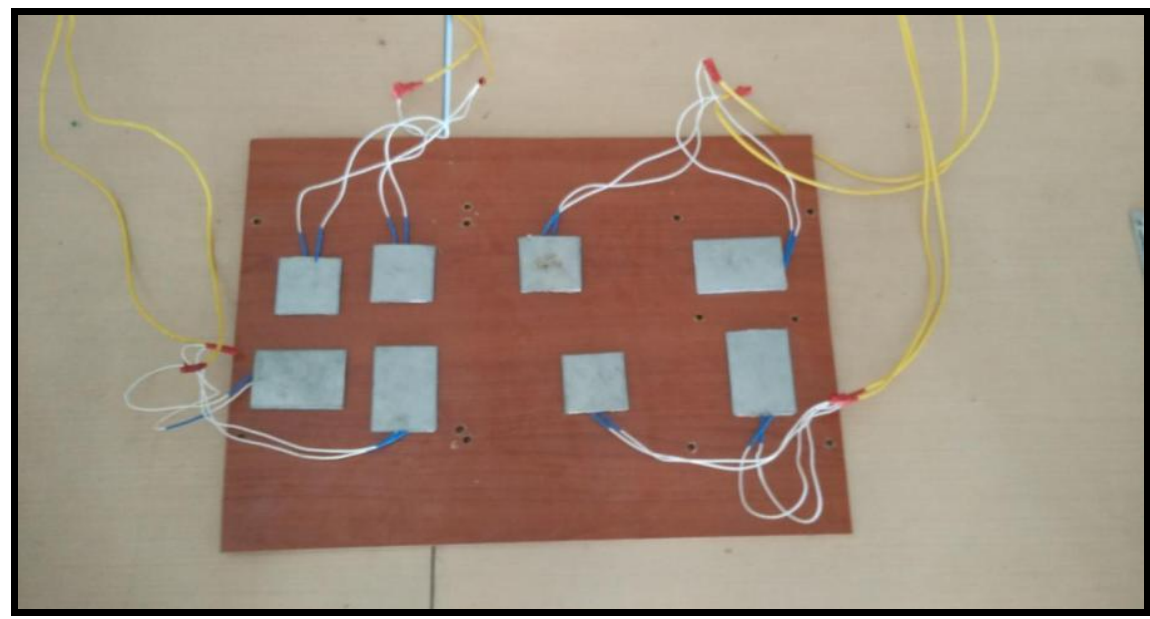

Fig. 2: Experimental setup without the heat spreaders

As seen above, the heaters are arranged in the same way as that of the phone. The heaters are run for 30 seconds time and were allowed to cool for another 5 minutes during which the peak temperatures are noted. Then the metal heat spreaders were attached and the temperatures were measured again. The temperatures were measured with the help of a thermal imaging camera. Figures 3 and 4 show the chipset covered with copper and aluminium spreaders respectively. 


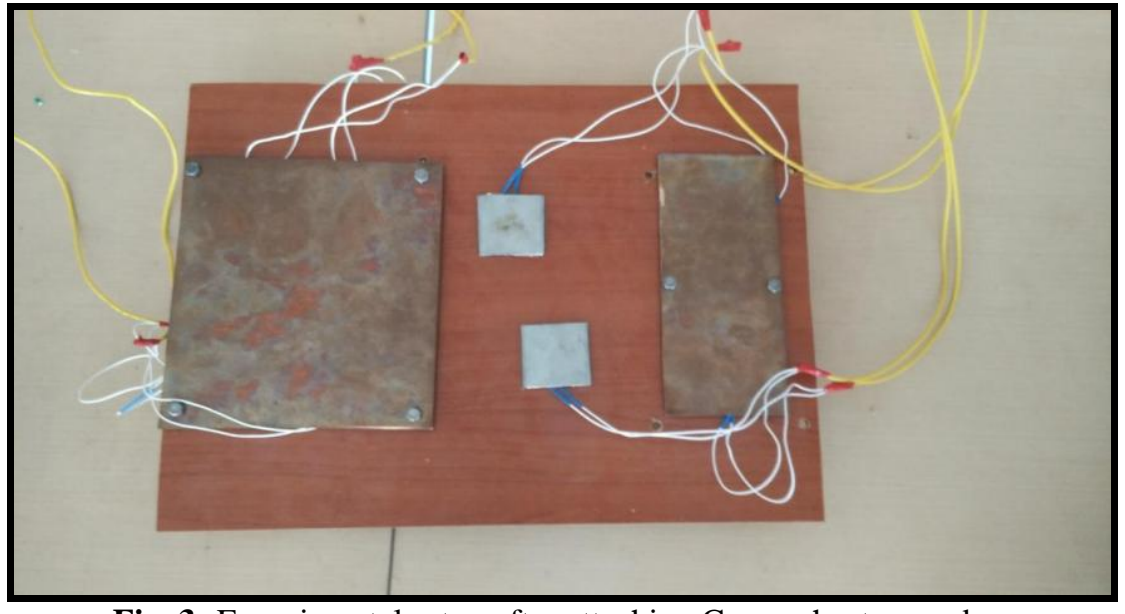

Fig. 3: Experimental setup after attaching Copper heat spreaders

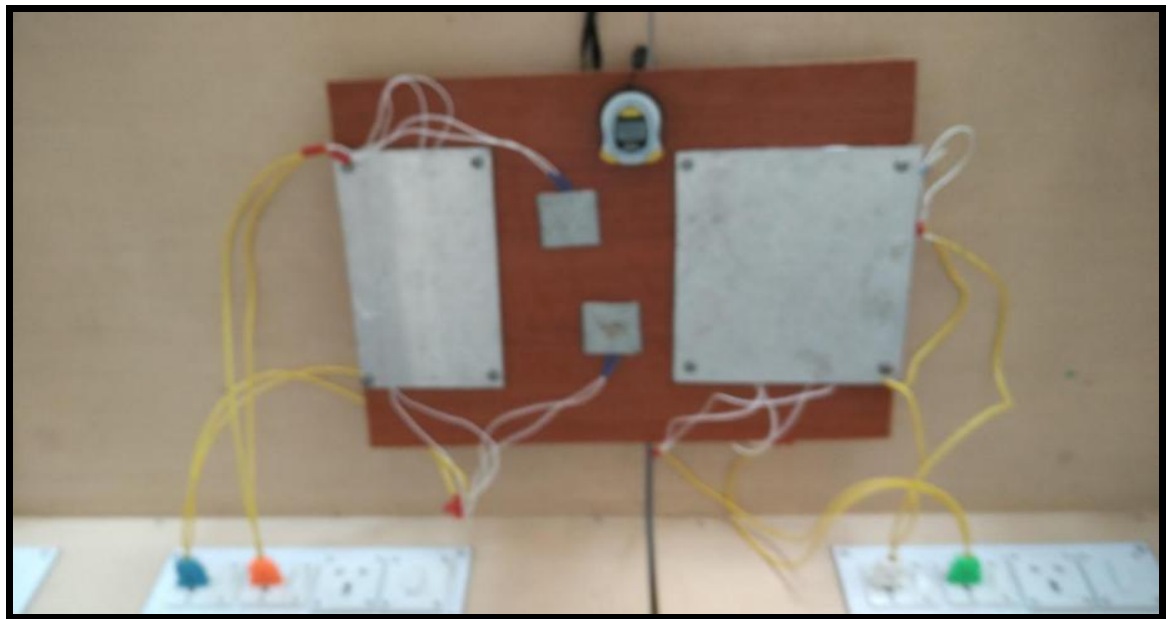

Fig.4: Experimental setup with Aluminium heat spreaders

\section{RESULTS AND DISCUSSION}

The simulation was run for two operating conditions of the phone:

Case 1. When both the mobile data and power consuming applications are being executed
Case 2. When only a power consuming in being executed

Case 1: When both mobile data and power consuming application are running

Boundary conditions:

The boundary condition to chips was given in terms of heat flux [14]

TABLE I: Boundary conditions for case 1

\begin{tabular}{|l|l|}
\hline Region & Heat flux $\left(\mathbf{W} / \mathbf{m}^{2}\right)$ \\
\hline Front internet chips & 50000 \\
\hline Back side processor chips & 10000 \\
\hline Front processor chips & 30000 \\
\hline
\end{tabular}

Convection mode of heat transfer was given for inner case and outer case [15]

TABLE II: Convection Boundary conditions for case 1

\begin{tabular}{|l|l|l|}
\hline Region & Film Coefficient $\left(\mathbf{W} / \mathbf{m}^{2} .{ }^{\circ} \mathbf{C}\right)$ & Ambient Temperature $\left({ }^{\circ} \mathbf{C}\right)$ \\
\hline Inner case & 30 & 35 \\
\hline Outer case & 50 & 30 \\
\hline
\end{tabular}

Figure 5 shows the front side of the chipset. 


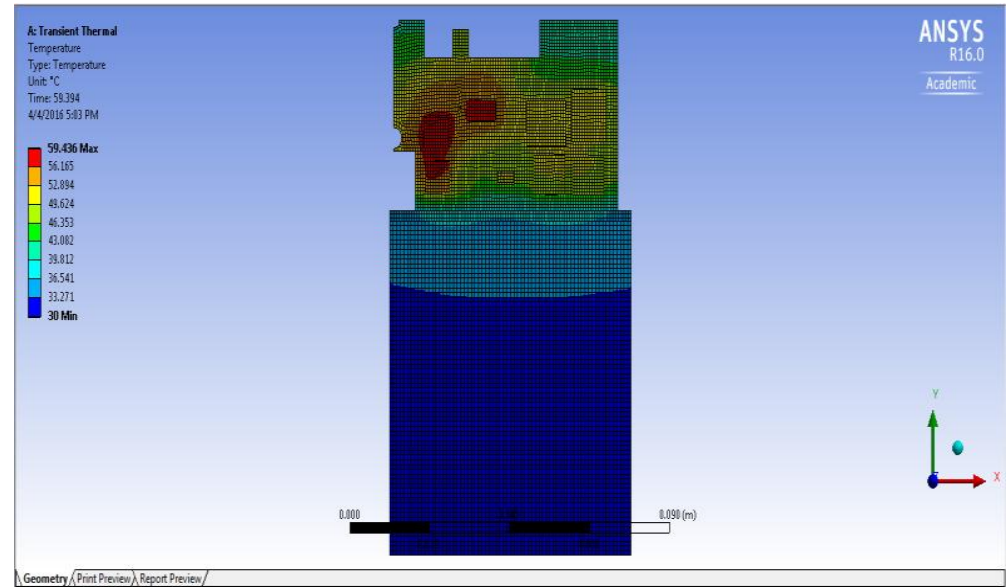

Fig. 5: Front side view of the chipset

It can be seen that the maximum temperature is $59.4^{\circ} \mathrm{C}$. The front net processor chips are hot due to high local heat flux density. The temperature distribution for the outer casing is not uniform as it has small patches of high temperature regions. This non uniform temperature patches will not be comfortable for the users.

Case 2: When a power consuming app is being executed.

Boundary conditions:

The boundary condition to chips were given in terms of heat flux.

TABLE III: Boundary conditions for case 2

\begin{tabular}{|l|l|}
\hline Region & Heat flux $\left(\mathbf{W} / \mathbf{m}^{2}\right)$ \\
\hline Front internet chips & 0 \\
\hline Back side processor chips & 20000 \\
\hline Front processor chips & 52000 \\
\hline
\end{tabular}

Convection was given as boundary condition for inner case and outer case.

TABLE IV: Convection Boundary conditions for case 2

\begin{tabular}{|l|l|l|}
\hline Region & Film Coefficient $\left(\mathbf{W} / \mathbf{m}^{2} .{ }^{\circ} \mathbf{C}\right)$ & Ambient Temperature $\left({ }^{\circ} \mathbf{C}\right)$ \\
\hline Inner case & 30 & 35 \\
\hline Outer case & 50 & 30 \\
\hline
\end{tabular}

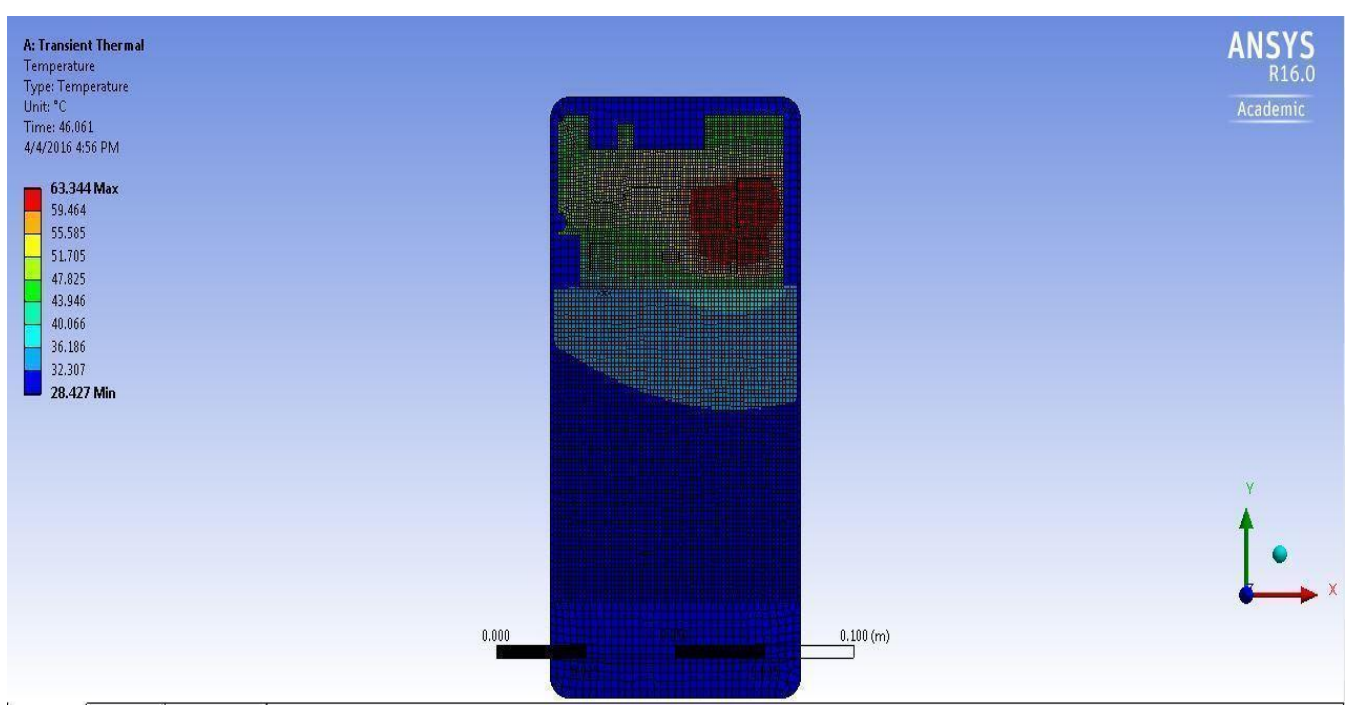

Fig. 6: Front side of the chipset 
Figure 6 above shows the temperature distribution. The maximum temperature for case 2 in phone is $63.34{ }^{\circ} \mathrm{C}$. The front snapdragon 610 processor chips are hot due to high local heat flux density of around $0.052 \mathrm{~W} / \mathrm{mm}^{2}$. The temperature distribution for the outer casing is not uniform as it has small patches of high temperature regions. This non-uniform temperature patches will not be comfortable for user.

Case 3: When Case 1 is run after attaching the Copper metal heat spreaders

Boundary conditions:

The boundary conditions were given in terms of heat flux.[14]

TABLE V: Boundary conditions for case 3

\begin{tabular}{|l|l|}
\hline Region & Heat flux $\left(\mathbf{W} / \mathbf{m}^{\mathbf{2}}\right)$ \\
\hline Front internet chips & 50000 \\
\hline Back side processor chips & 10000 \\
\hline Front processor chips & 30000 \\
\hline
\end{tabular}

Convection was given as a boundary condition for inner and outer case.[15]

TABLE VI: Convection Boundary conditions for case 3

\begin{tabular}{|l|l|l|}
\hline Region & Film Coefficient $\left(\mathbf{W} / \mathbf{m}^{\mathbf{2}} \cdot{ }^{\circ} \mathbf{C}\right)$ & Ambient Temperature $\left({ }^{\circ} \mathbf{C}\right)$ \\
\hline Inner case & 30 & 35 \\
\hline Outer case & 50 & 30 \\
\hline
\end{tabular}

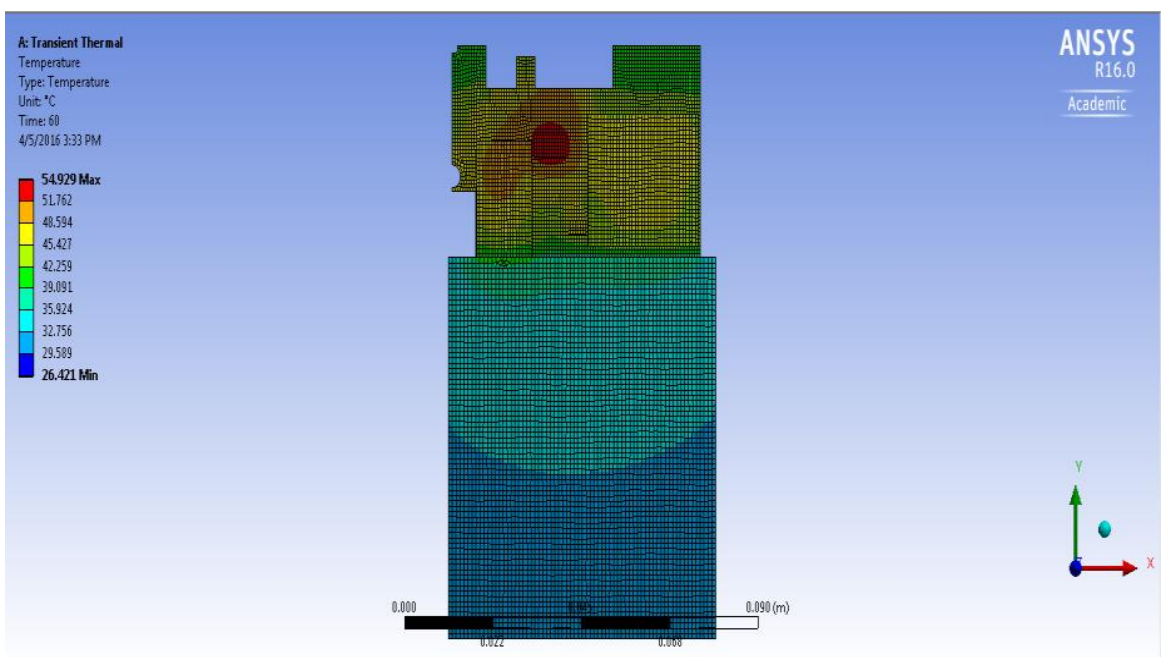

Fig. 7: Front side of the chip with metal heat spreaders

Figure 7 shows the temperature distribution. The maximum temperature for case 3 in phone is $54.93{ }^{\circ} \mathrm{C}$. There is a reduction of $4.51^{\circ} \mathrm{C}$ as compared to case 1 due to the usage of Copper heat spreaders. The temperature distribution for the outer casing is uniform as it has big patches of high temperature regions. This uniform temperature patches will be comfortable for the users to hold the phone.

Case 4: When Case 2 is run after attaching the Copper metal heat spreaders

Boundary conditions:

The boundary condition was given in terms of heat flux.

TABLE VII: Boundary conditions for case 4

\begin{tabular}{|l|l|}
\hline Region & Heat flux $\left(\mathbf{W} / \mathbf{m}^{2}\right)$ \\
\hline Front internet chips & 0 \\
\hline Back side processor chips & 20000 \\
\hline Front processor chips & 52000 \\
\hline
\end{tabular}

Convection was given as boundary condition for inner case and outer case. 
TABLE VIII: Convection boundary conditions for case 4

\begin{tabular}{|l|l|l|}
\hline Region & Film Coefficient $\left(\mathbf{W} / \mathbf{m}^{2} \cdot{ }^{\circ} \mathbf{C}\right)$ & Ambient Temperature $\left({ }^{\circ} \mathbf{C}\right)$ \\
\hline Inner case & 30 & 35 \\
\hline Outer case & 50 & 30 \\
\hline
\end{tabular}

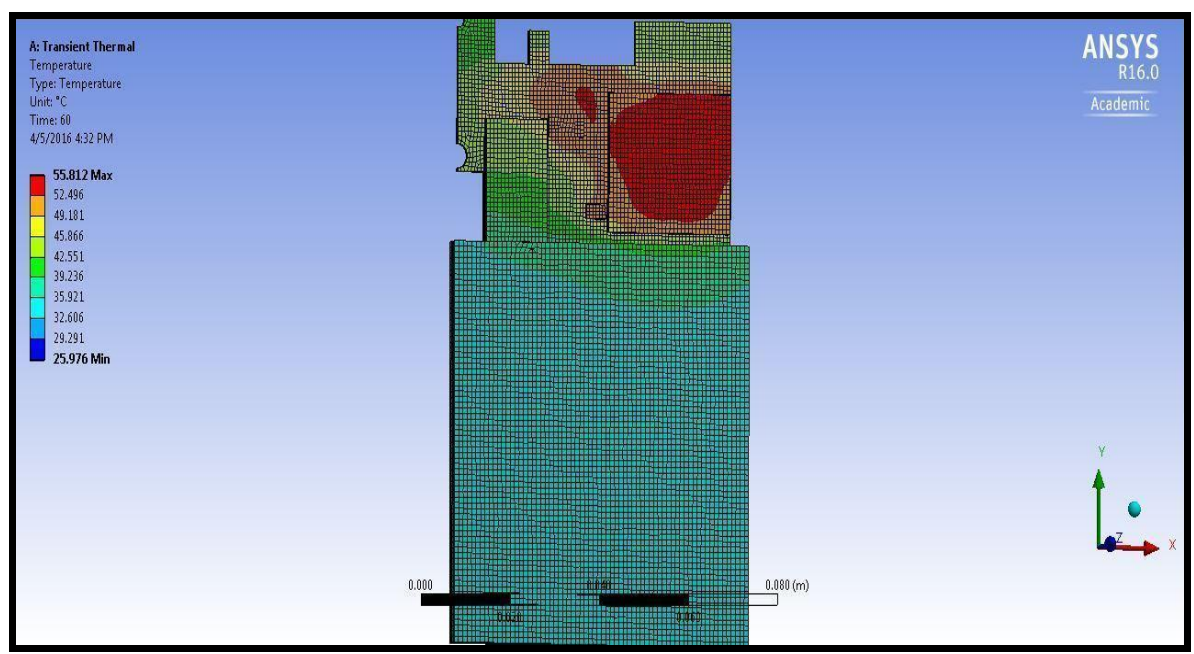

Fig.8: Front side of the chip with metal heat spreaders

Figure 8 shows the temperature distribution for this case. The maximum temperature for case 4 in phone is $55.8{ }^{\circ} \mathrm{C}$. There is reduction of about $7.5^{\circ} \mathrm{C}$ due to the usage of $.5 \mathrm{~mm}$ Copper heat spreaders. The front snapdragon 610 processor chips are hot due to high local heat flux density of around $0.052 \mathrm{~W} / \mathrm{mm}^{2}$. The temperature distribution for the outer casing is uniform as it has two big patches of high temperature regions. This uniform temperature patches will be comfortable for the users.

Case 5: When Case 1 is run after attaching the Aluminium metal heat spreaders

Boundary conditions:

The boundary conditions were given in terms of heat flux.[14]

TABLE IX: Boundary conditions for case 5

\begin{tabular}{|l|l|}
\hline Region & Heat flux $\left(\mathbf{W} / \mathbf{m}^{2}\right)$ \\
\hline Front internet chips & 50000 \\
\hline Back side processor chips & 10000 \\
\hline Front processor chips & 30000 \\
\hline
\end{tabular}

Convection was given as a boundary condition for inner and outer case.[15]

TABLE X: Convection boundary conditions for case 5

\begin{tabular}{|l|l|l|}
\hline Region & Film Coefficient $\left(\mathbf{W} / \mathbf{m}^{\mathbf{2}} \cdot{ }^{\circ} \mathbf{C}\right)$ & Ambient Temperature $\left({ }^{\circ} \mathbf{C}\right)$ \\
\hline Inner case & 30 & 35 \\
\hline Outer case & 50 & 30 \\
\hline
\end{tabular}

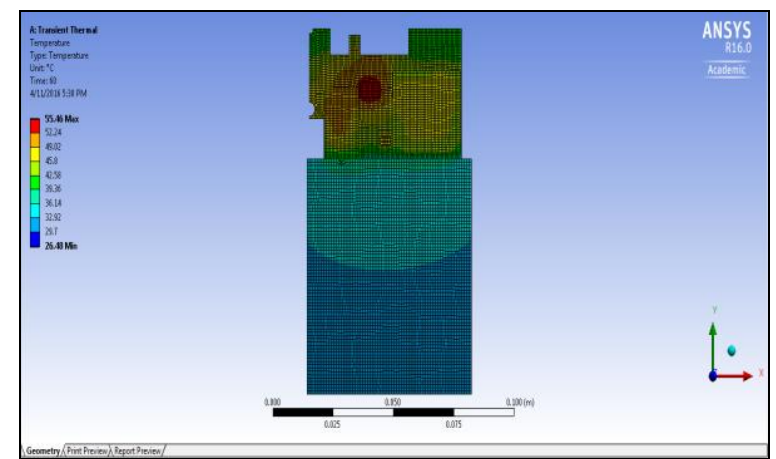

Fig. 9: Front side of the chip with Aluminium metal heat spreaders 
The maximum temperature for case 5 in phone is $55.46{ }^{\circ} \mathrm{C}$. There is a reduction of $3.98^{\circ} \mathrm{C}$ as compared to case 1 due to the usage of Aluminium heat spreaders but there is increase of $0.531^{\circ} \mathrm{C}$ due to the usage of Aluminium material for heat spreaders instead of Copper as in case 3. The temperature distribution for the outer casing is uniform as it has big patches of high temperature regions. This uniform temperature patches will be comfortable for the users to hold the phone.

Case 6: When Case 2 is run after attaching the Aluminium metal heat spreaders

Boundary conditions:

The boundary condition was given in terms of heat flux.

TABLE XI: Boundary conditions for case 6

\begin{tabular}{|l|l|}
\hline Region & Heat flux $\left(\mathbf{W} / \mathbf{m}^{2}\right)$ \\
\hline Front internet chips & 00 \\
\hline Back side processor chips & 20000 \\
\hline Front processor chips & 52000 \\
\hline
\end{tabular}

Convection was given as boundary condition for inner case and outer case.

TABLE XII: Convection boundary conditions for case 6

\begin{tabular}{|l|l|l|}
\hline Region & Film Coefficient $\left(\mathbf{W} / \mathbf{m}^{\mathbf{2}} .{ }^{\circ} \mathbf{C}\right)$ & Ambient Temperature $\left({ }^{\circ} \mathbf{C}\right)$ \\
\hline Inner case & 30 & 35 \\
\hline Outer case & 50 & 30 \\
\hline
\end{tabular}

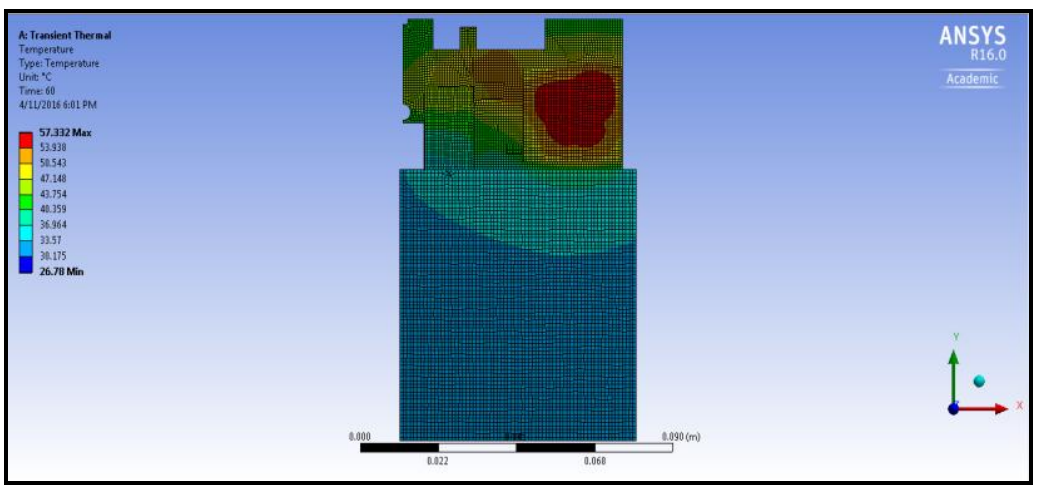

Fig 10: Front side of the chipset with Aluminium heat spreaders

The maximum temperature for case 6 in phone is $57.33{ }^{\circ} \mathrm{C}$. There is a reduction of $6.1{ }^{\circ} \mathrm{C}$ as compared to case 1 due to the usage of Aluminium heat spreaders but there is increase of $1.52^{\circ} \mathrm{C}$ due to the usage of Aluminium material for heat spreaders instead of Copper as in case 4. The temperature distribution for the outer casing is uniform as it has big patches of high temperature regions. This uniform temperature patches will be comfortable for the users to hold the phone.

Case 7: When Case 3 is run with micro heat taps Boundary conditions:

The boundary conditions were given in terms of heat flux.[14]

TABLE XIII: Boundary conditions for case 7

\begin{tabular}{|l|l|}
\hline Region & Heat flux $\left(\mathbf{W} / \mathbf{m}^{2}\right)$ \\
\hline Front internet chips & 50000 \\
\hline Back side processor chips & 10000 \\
\hline Front processor chips & 30000 \\
\hline
\end{tabular}

Convection was given as a boundary condition for inner and outer case.[15]

TABLE XIV: Convective boundary conditions for case 7

\begin{tabular}{|l|l|l|}
\hline Region & Film Coefficient $\left(\mathbf{W} / \mathbf{m}^{\mathbf{2}} .{ }^{\circ} \mathbf{C}\right)$ & Ambient Temperature $\left({ }^{\circ} \mathbf{C}\right)$ \\
\hline Inner case & 30 & 35 \\
\hline Outer case & 50 & 30 \\
\hline
\end{tabular}




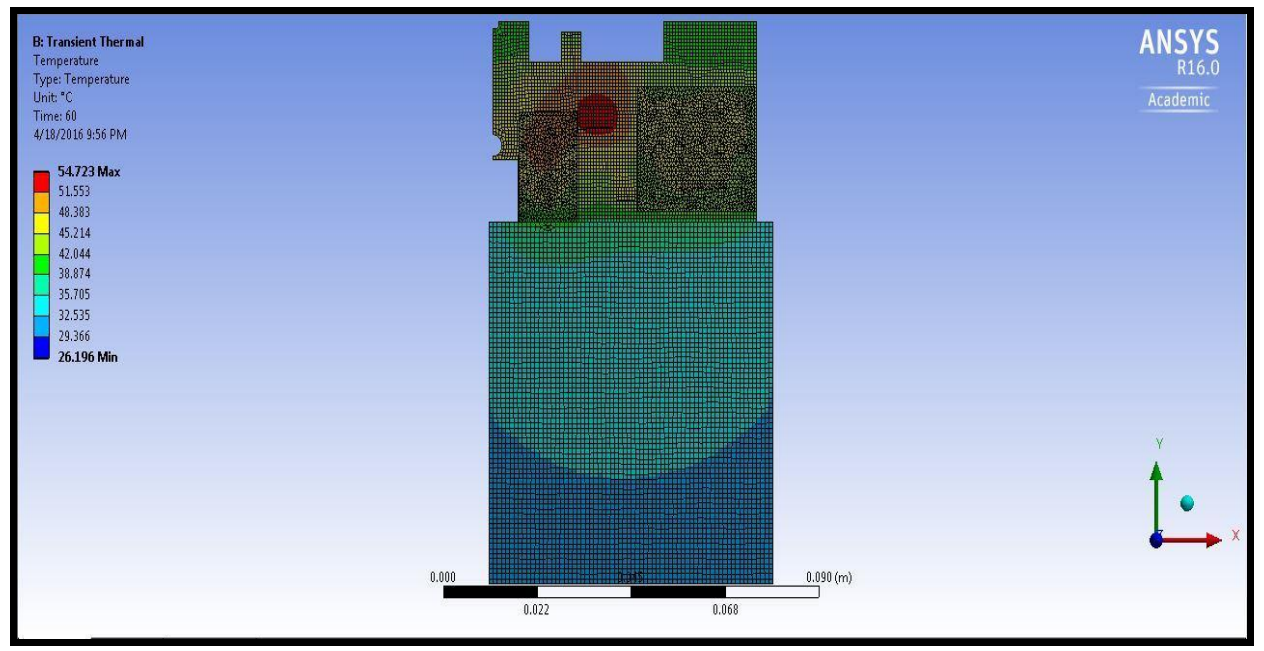

Fig.11 Copper heat spreader with micro heat taps run for case 3

uniform as it has big patches of high temperature

The maximum temperature for case 15 in regions. This uniform temperature patches will be phone is $54.723^{\circ} \mathrm{C}$. There is a reduction of $4.713^{\circ} \mathrm{C}$ as compared to case 1 due to the usage of Copper heat spreaders with micro heat taps and there is also decrease of $.201^{\circ} \mathrm{C}$ due to the usage of micro heat taps for heat spreaders instead of full Copper as in case 3 . The temperature distribution for the outer casing is comfortable for the users to hold the phone.

\section{Case 8: When Case 4 is run with micro heat taps}

Boundary conditions:

The boundary condition was given in terms of heat flux.

TABLE XV: Boundary conditions for case 8

\begin{tabular}{|l|l|}
\hline Region & Heat flux $\left(\mathbf{W} / \mathbf{m}^{2}\right)$ \\
\hline Front internet chips & 0 \\
\hline Back side processor chips & 20000 \\
\hline Front processor chips & 52000 \\
\hline
\end{tabular}

Convection was given as boundary condition for inner case and outer case.

TABLE XVI: Convection boundary conditions for case 8

\begin{tabular}{|l|l|l|}
\hline Region & Film Coefficient $\left(\mathbf{W} / \mathbf{m}^{2} \cdot{ }^{\circ} \mathbf{C}\right)$ & Ambient Temperature $\left({ }^{\circ} \mathbf{C}\right)$ \\
\hline Inner case & 30 & 35 \\
\hline Outer case & 50 & 30 \\
\hline
\end{tabular}

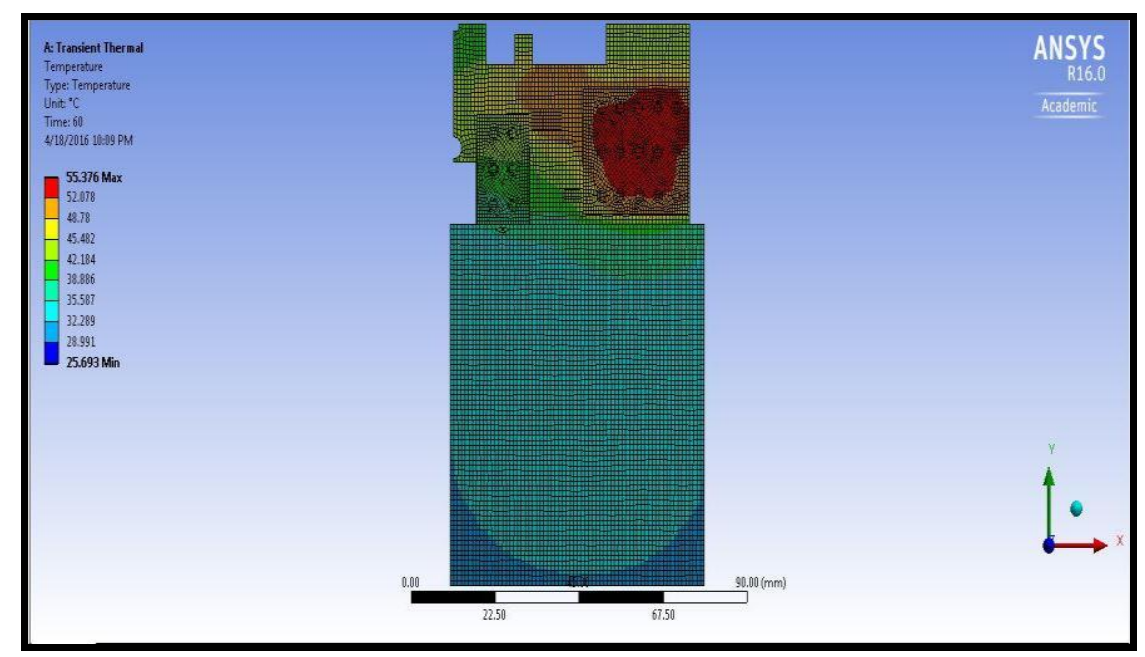

Fig. 12 Copper heat spreader with micro heat taps run for case 4 
The maximum temperature for case 15 in phone is $55.376{ }^{\circ} \mathrm{C}$. There is a reduction of $8^{\circ} \mathrm{C}$ as compared to case 1 due to the usage of Copper heat spreaders with micro heat taps and there is also decrease of $.511^{\circ} \mathrm{C}$ due to the usage of micro heat taps for heat spreaders instead of full Copper as in case 4. The temperature distribution for the outer casing is uniform as it has big patches of high temperature regions. This uniform temperature patches will be comfortable for the users to hold the phone. It has been observed similarly with Aluminium heat spreaders containing heat taps of $1 \mathrm{~mm}$ diameter that there is a small reduction in temperature.

\section{Influence of Heat Spreader Thickness:}

The Figure 13 below shows the decreasing temperatures with increase in thickness of the heat spreaders for both Copper and Aluminium plates

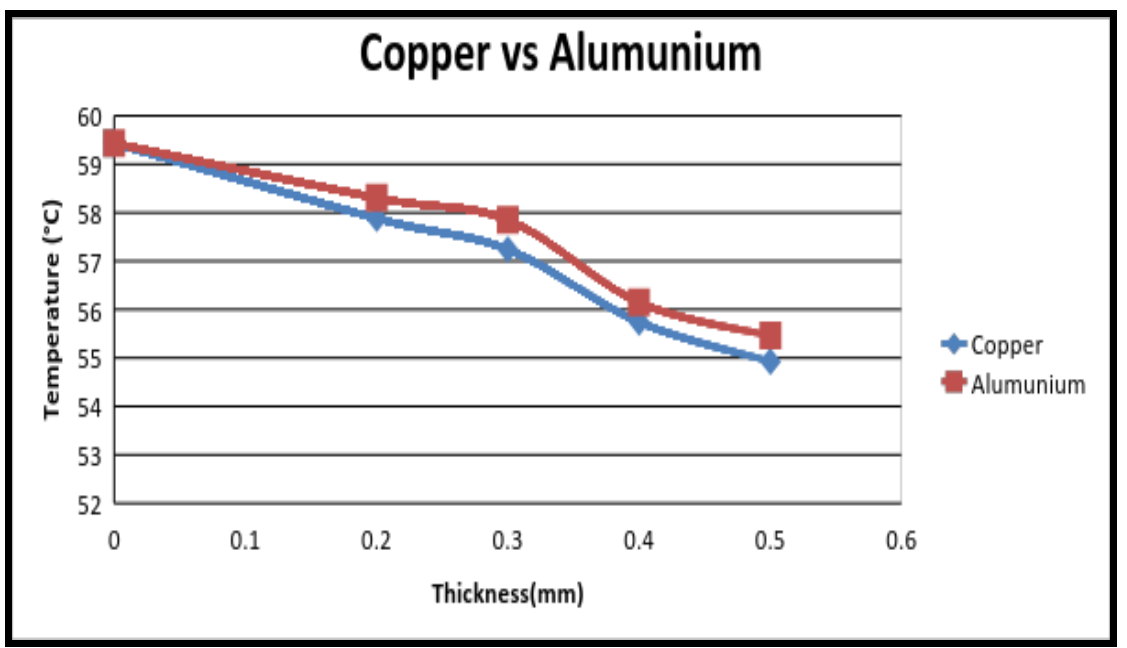

Fig. 13 Graph of temperature v/s Thickness for both Copper and Aluminium heat spreaders

When the thickness of the plate increases, the heat capacity of the plate increases so it is capable of absorbing more heat and there by contributes to reduce the temperature of processor chips.

\section{Influence of Heat Taps:}

The presence of micro heat taps in a heat spreader actually lowers the temperature by around $.3-.5^{\circ} \mathrm{C}$ in both Aluminium as well as Copper even in this case. It is also a good design criteria because it helps in overall weight reduction of the heat spreader due to added holes. The high local heat flux density in this case does not act as a thermal shield due to the presence of heat taps.

\section{Experimental setup results}

\section{When the setup is run in normal condition}

The setup without the heat spreaders was first heated for a 10 secs and then kept idle for 3 minutes after which the thermal image is taken.

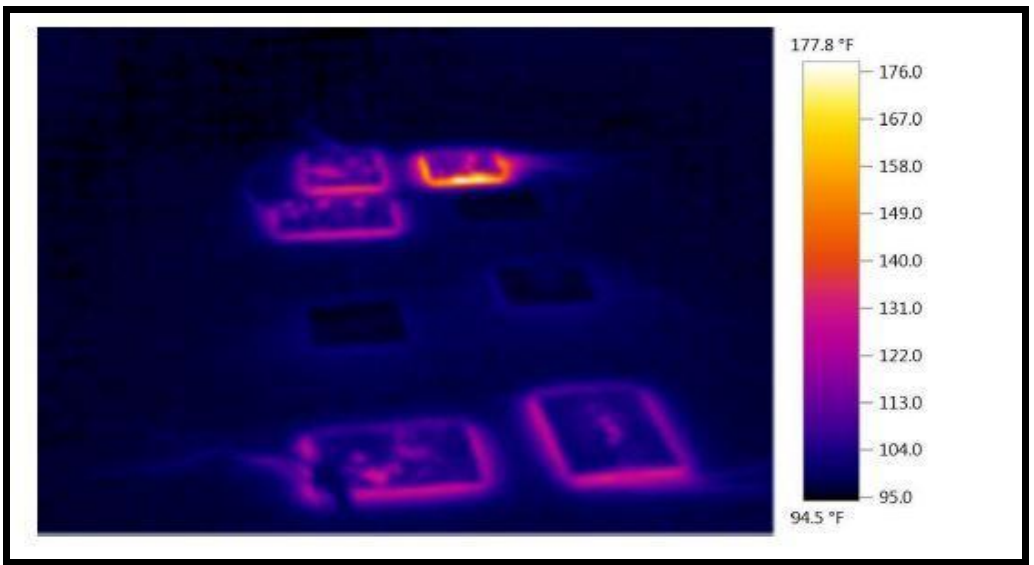

Fig. 14 Thermal image of setup in normal condition 
The peak temperature attained during this stage is $70^{\circ} \mathrm{C}$.

When setup is run after attaching Copper heat spreaders

The setup, after attaching the Copper plates is run for another 10 secs time and then kept idle for 3 minutes for the thermal image to be taken.

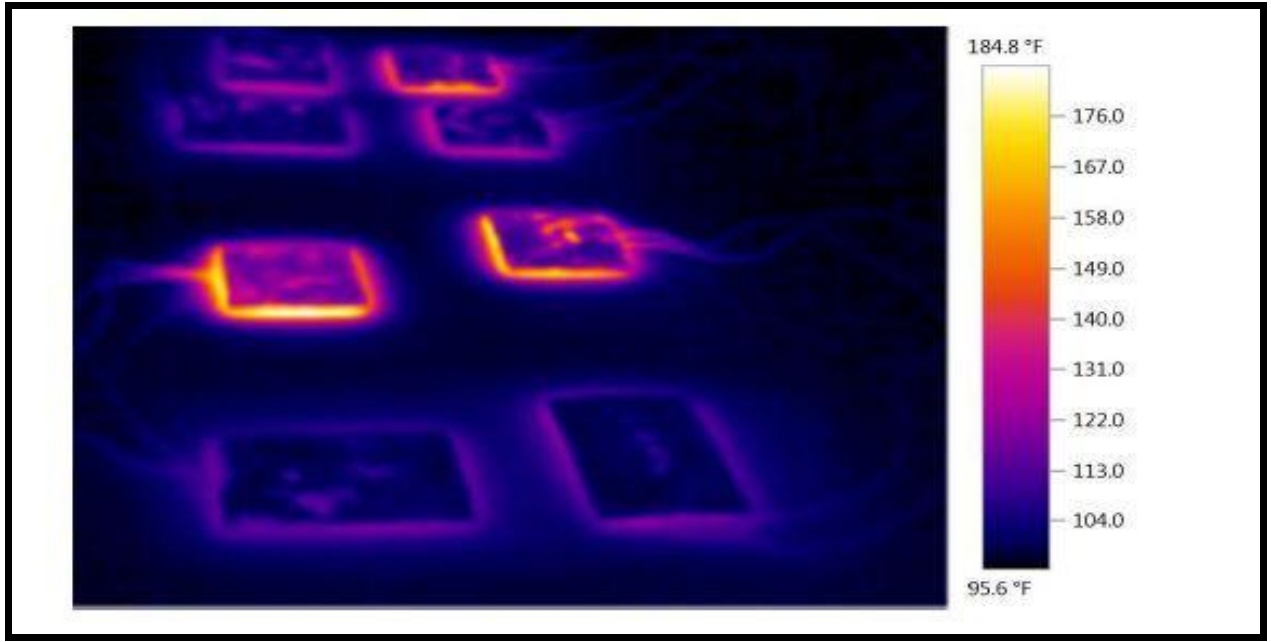

Fig. 15 Thermal image of setup after attaching Copper heat spreaders

There is a decrease in the peak temperature of the setup after attaching the Copper heat spreaders. The peak temperature attained is $62^{\circ} \mathrm{C}$.

\section{When setup is run after attaching Aluminium heat spreaders}

The setup, after attaching the Aluminium plates is run for another $10 \mathrm{secs}$ and then kept idle for 3 minutes for the thermal image to be taken.

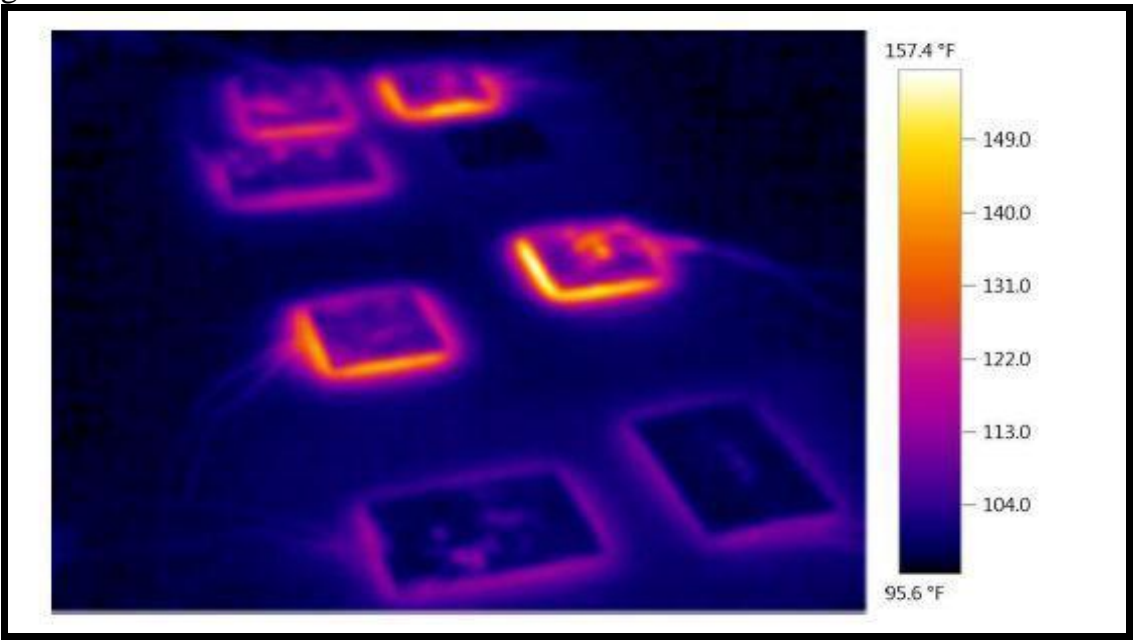

Fig. 16 Thermal image of setup after attaching Aluminium heat spreaders

There is a decrease in the peak temperature attained in the setup after attaching the Aluminium heat spreaders. The peak temperature attained is $65^{\circ} \mathrm{C}$.

\section{CONCLUSION}

A teardown analysis of a Mi4i smart phone was used to develop the thermal model of the phone. Transient Thermal simulations in Ansys 16.0 for the phone were performed for different thicknesses of heat spreader $(0.2,0.3,0.4$ and $0.5 \mathrm{~mm})$ and for different materials (Aluminium and Copper). Good heat conduction paths within the phone system are essential for lower processor temperature. As metallic spreaders and metallic spreaders with heat taps can serve to create such thermal paths. The usage of Copper heat spreaders of $0.5 \mathrm{~mm}$ thick reduced the maximum temperature by $4.5^{\circ} \mathrm{C}$ and $7.53^{\circ} \mathrm{C}$ for case 1 and 2 respectively. After the introduction of heat taps in the above mentioned case a total decrease of $4.71^{\circ} \mathrm{C}$ and $7.97^{\circ} \mathrm{C}$. It was observed 
that there is a trade off between lower processor temperature and weight of heat spreader. Although Aluminium heat spreader of $0.5 \mathrm{~mm}$ thickness(1.9 grams) weighed less than Copper (6.02 grams) by 4.114 grams but Copper has greater temperature drop because of its superior thermal conductivity. When local heat flux density of processor chips is high usage of metallic spreaders below $0.4 \mathrm{~mm}$ thick acted as a thermal shield therefore heat spreaders of thickness more than $.4 \mathrm{~mm}$ is only advisable to use for this phone. The experimental setup consisting of mica heaters, Copper and Aluminium heat spreaders plates validated the numerical results by giving lower maximum temperature for Copper followed by Aluminium and without heat spreader.

\section{ACKNOWLEDGMENT}

The authors acknowledge Dr. Pratibha Nalini and Dr. Manimaran of the School of Mechanical and Building Sciences, VIT Chennai, for their valuable suggestions during the period of research.

\section{REFERENCES}

[1] Lee, L., Gerlach, D. W., and Joshi, Y. K., "Parametric Thermal Modeling of Heat Transfer In Handheld Electronic Devices," Proc. 11th ITHERM Conference, May, 2008, pp. 604-609.

[2] Luo, Z., Cho, H., Luo, X., Cho, K., "System thermal analysis for mobile phone," Applied Thermal Engineering, Vol. 28, 2008, pp. 1889-1895.

[3] Grimes, R., Walsh, E., and Walsh, P., "Active cooling of a mobile phone handset," Applied Thermal Engineering, Vol. 30, 2010, pp. 2363-2369.

[4] CFD analysis of electronic chip cooling by Saroj Kumar Patra, NIT Rourkela (2007).

[5] Victor, C, Steve, M, Jon, A, and Ken, G," A Figure of Merit for Smartphone Thermal Management", Microelectronics Journal Vol 422015.

[6] Yusuke Tomizawa, Katsuhiko Sasaki, Akiyoshi Kuroda, Ryo Takeda, Yoshihiko Kaito, "Experimental and numerical study on phase change material (PCM) for thermal management of mobile devices", Applied Thermal Engineering Dec 2015.

[7] Haoshan Ge and Jing Liu," Keeping Smartphones Cool with Gallium Phase Change Material", Journal of Heat Transfer (ASME), Vol.135 May 2015.

[8] Siva P. Gurrum, Darvin R. Edwards, Thomas Marchand-Golder, Jotaro Akiyama, Satoshi Yokoya, Jean- Francois Drouard, Franck Dahan, Generic Thermal Analysis for Phone and Tablet Systems”, Applied Thermal Engineering, Vol. 32, 2012

[9] Maciej Jaworski," Thermal performance of heat spreader for electronics cooling with incorporated phase change material", Applied Thermal Engineering Vol 35 Oct 2012

[10] Ronan Grimes, Ed Walsh, Pat Walsh, "Active cooling of a mobile phone handset", Applied Thermal Engineering 2012

[11] Egan, Eric, Amon Cristina H., "Thermal Management Strategies for Embedded Electronic Components of Wearable Computers", Journal of Electronic Packaging, June 2000, Vol.122, Page 98-106.

[12] Simionescu, F., Meir, A. J., and Harris, D. K., "Approximation of an optimal convective heat transfer coefficient", Optimum Control Appl. Meth. (In press), John Wiley \& Sons, Ltd. 2006.

[13] T.T Lee," Thermal management of handheld telecommunication products", "Application of CFD Technology to Electronic Thermal Management", IEEE Transactions on Components, Packaging, and Manufacturing Technology Part B, Vol. 18, May, 1998.

[14] Raghu Bc,Anand SN,Vitala HR," Thermal Flux assessment and Drop test of smart phone-A case study", International Journal of Scientific Engineering and Applied Science (IJSEAS) - Volume-1, Issue-3, June2015

[15] Jayachandraiah, "Modeling and Simulation 3D Heat Conduction for Sony Xperia Tipo Model Mobile Phone".2013

\section{AUTHOR PROFILE}

Author1 K. Abinav, Student, VIT University, Chennai Campus

Author2 P. Palani Rajeshwar, Student, VIT University, Chennai Campus

Author 3 Jerry S Punnoose, Student, VIT University, Chennai Campus

Author 4 Dr. Joseph Daniel, Associate Professor, VIT University, Chennai CampusAuthor 5 Dr. M. Sreekanth, Associate Professor, VIT University, Chennai Campus 